\title{
Total correction of Fallot's tetralogy in patients aged less than I year
}

\author{
G. M. Rees ${ }^{1}$ and Albert Starr \\ From the Division of Cardiopulmonary Surgery, University of Oregon Medical School, \\ Portland, Oregon, U.S.A.
}

Nine patients aged less than I year who developed severe anoxic attacks complicating Fallot's tetralogy were treated by one-stage total surgical correction. Eight survived and one died after a technical complication. Two further patients developed serious problems in the form of a severe respiratory tract infection and a hemiparesis, respectively; both, however, have made virtually complete recoveries. Relief of outflow tract obstruction is supported by haemodynamic data. All 8 survivors continue to make good progress.

In such patients with a suitable anatomical situation, one-stage total correction appears to offer a satisfactory alternative surgical approach to those currently advised.

Severe symptoms in young children with tetralogy of Fallot are generally treated by palliative operations designed to increase pulmonary blood flow rather than by a one-stage total correction. Though the risks of the former procedures are said to be lower than those of the latter (Sabiston et al., I964; Kaplan et al., 1968; Somerville et al., 1969; Hallman, 1968), all have inherent disadvantages (Woodson et al., 1969).

The results obtained in this unit after one-stage total correction in patients aged between $I$ and 3 years with severe symptoms are comparable to those attained by palliation (Burnell et al., 1969; Woodson et al., 1969). These have led us to adopt a policy of treatment by total correction for infants who developed serious symptoms before the age of I year. We here report our early results in this group.

\section{Patients and methods}

Nine patients, 4 girls and 5 boys, are included (Table). Mean age was $7 \frac{1}{2}$ months (range 3 to II months). Average weight at the time of operation was $6.9 \mathrm{~kg}$ (range $4.3-8.8 \mathrm{~kg}$ ). In all cases the prime indication for operation was the occurrence of severe anoxic spells which were increasing both in frequency and intensity. All patients had central cyanosis at rest, a loud systolic bruit heard best at the left sternal edge, and a single second sound. Case 3 had additional congenital defects with cleft palate, low set ears, absent thymus, and reduction of parathyroid tissue (Di George's syndrome).

Received Io April 1973.

1 Present address: St. Bartholomew's Hospital, London E.C.I.
Cardiac catheterization with cineangiography was performed in all before operation.

In each case a large ventricular septal defect was seen in association with pronounced infundibular stenosis; Case 3 had associated pulmonary valve stenosis. Angiographic appearances indicated that the pulmonary artery was of adequate size in all. At operation, however, 3 (Cases $1,6,7$ ) required a patch to enlarge the outflow tract of the right ventricle. Atrial septal defects were noted in addition in Cases 1,3 , and 7. Mean preoperative right ventricular pressure measured $83 \mathrm{mmHg}$, ranging from $70 \mathrm{~mm}$ to $100 \mathrm{mmHg}$.

Before operation all were given digitoxin to between half to two-thirds of the total recommended digitalizing dose $(0.05 \mathrm{mg} / \mathrm{kg}$ body weight).

\section{Operation}

Each procedure was undertaken through a median sternotomy. Cardiopulmonary bypass was instituted after cannulation of the ascending aorta and superior and inferior venae cavae via the right atrium, using high flow perfusion $\left(2.41 . / \mathrm{m}^{2}\right.$ per minute) of heparinized blood with mannitol and cooling to between $30^{\circ} \mathrm{C}$ and $34^{\circ} \mathrm{C}$. The Bentley infant bubble oxygenator was used in all. After caval snaring the right ventricle was incised vertically. The outflow tract was examined and infundibular stenosis carefully resected, leaving intact, the crista supraventricularis on the floor of the outflow tract. During aortic clamping for approximately 15 to 20 minutes, interrupted 'OOOO' sutures were used to secure a 'teflon' patch over the ventricular septal defect. The left ventricle was decompressed via the septal defect before the final sutures were tied. The outflow tract was then examined with a Bakes dilator. In 3 cases (Cases I, 6 , and 7) a patch of woven felt was necessary to enlarge 
TABLE Clinical details

\begin{tabular}{|c|c|c|c|c|c|c|}
\hline Case No. & Age (mth) & Sex & Weight (kg) & $\begin{array}{l}\text { Preoperative right } \\
\text { ventricular pressures }\end{array}$ & $\begin{array}{l}\text { Preoperative arterial } \\
\text { oxygen saturation }(\%)\end{array}$ & $\begin{array}{l}\text { Postoperative right ven- } \\
\text { tricular systolic pressures }\end{array}$ \\
\hline I & II & F & $8 \cdot 4$ & $100 / 9$ & 71 & 60 \\
\hline 2 & 3 & $\mathbf{M}$ & $4 \cdot 3$ & $74 / 5$ & 74 & 38 \\
\hline 3 & 8 & $\mathbf{M}$ & $6 \cdot 3$ & $75 / 8$ & 70 & - \\
\hline 4 & Io & $\mathrm{F}$ & $7 \cdot 4$ & $78 / 2$ & 91 & 37 \\
\hline 5 & 9 & M & $8 \cdot 8$ & $85 / 6$ & 71 & 30 \\
\hline 6 & I0 & M & $8 \cdot 2$ & $70 / 4$ & 74 & 40 \\
\hline 7 & 5 & $\mathrm{~F}$ & $5 \cdot 0$ & $100 / 4$ & 90 & 38 \\
\hline 8 & 7 & $\mathrm{~F}$ & $6 \cdot 3$ & $85 / 10$ & 92 & 35 \\
\hline 9 & 5 & $\mathbf{M}$ & $7 \cdot 5$ & $85 / 4$ & 75 & 40 \\
\hline
\end{tabular}

the pulmonary artery. In addition, in Case I, an atrial septal defect was closed.

The right ventricle was repaired using continuous 'OOO' sutures; and cardiopulmonary bypass was discontinued. Atrial and right ventricular pacemaker wires were attached and the chest was closed with drainage of pericardial cavity.

After operation the patients were extubated and nursed in an oxygen tent for the first 4 days. Full digitalization was achieved and routine attention was given to fluid and electrolyte therapy, fluid being limited to $50 \mathrm{ml} / \mathrm{kg}$ per 24 hours.

\section{Results}

Six patients had an uneventful postoperative course. Three patients however developed serious complications from which one died.

During resection of the infundibular stenosis in Case 3, a sinus of Valsalva was entered. Though this was repaired, pronounced aortic regurgitation followed distortion of the aortic valve: this was impossible to correct and proved fatal.

Case 4 developed a postoperative respiratory tract infection, with copious secretions. Tracheostomy was required on the fourth postoperative day; after this her condition rapidly improved.

Case I was noted to have a right hemiparesis on the fifth postoperative day. This gradually improved and permanent disability is minimal.

Four patients (Cases I, 4, 7, and 8) developed electrocardiographic evidence of right bundlebranch block; in no case was complete heart block produced, sinus rhythm being maintained after operation in all. Since discharge from hospital, all have been followed up regularly, but no further complications have been encountered.

During the same period, 20 additional cases of Fallot's tetralogy were seen in patients aged less than I year. Seven patients were severely cyanosed with profound hypoxaemia: all had anatomy unfavourable for total correction either due to pulmonary atresia or a severely hypoplastic pulmonary artery. This group was treated by systemic to pulmonary artery anastomosis. One patient was slightly cyanosed, but operation was deferred until the correction of concomitant tracheo-oesophageal fistula. Twelve patients were not cyanosed and were asymptomatic. The serious and progressive nature of tetralogy of Fallot diagnosed in infancy is shown by their subsequent course. Six required urgent correction in early childhood with three operative deaths. Three died without operation, one of choanal atresia and two of cerebrovascular accidents. Of three remaining patients, one with mild tetralogy has developed increasing cyanosis and is awaiting total correction. Two have complete pulmonary atresia with an adequate sized persistent ductus arteriosus.

\section{Discussion}

Results associated with the total correction of Fallot's tetralogy following Lillehei's first intracardiac corrective operation in 1955 have been, in general, satisfactory. Most experienced centres claim overall mortality rates of Io per cent or less (Kirklin, 1969; Gotsman et al., 1969).

Total correction in a patient aged less than I year was first reported by Benson, Joseph, and Ross (1962). Results of operations on somewhat older patients using deep hypothermia were reported by McMillan, Johnson, and Machell (1965) and by Dobell, Charette, and Chugtai (1968). The expectation of similar results after total correction in the very young may, however, be unrealistic as the indications for operation in the latter group (hypoxaemic attacks and/or heart failure) are very different from those in older patients where the main problem is diminished exercise tolerance (Benson et al., 1962). Unsatisfactory results (Gotsman et al., 1969) after total correction in the very young have led to advocacy of palliative short procedures, to be followed in most at a later date by a total correction.

Unfortunately, palliative procedures have many disadvantages (Kaplan et al., 1968). Failure of the 
right ventricular outflow tract to dilate with occasional atresia after systemic artery to pulmonary artery anastomosis has been described (Lillehei et al., 1955; Sabiston et al., 1964). Closed pulmonary valvotomy (Brock, 1948, 1959) appears to approach the problem more directly but is associated with the disadvantages of blind intracardiac procedures. The problems associated with aorta to right pulmonary artery anastomosis (Waterston's operation): difficulty in controlling stomal size, kinking of the right pulmonary artery, selective perfusion of the right lung with frequent occurrence of oedema of the right lung, have been recorded (Somerville et al., 1969). No mortality was encountered in this group though it is noted that only one patient was aged less than I year.

Palliative procedures tend in addition to add to the technical difficulties of total correction at a later date which may or may not increase the overall mortality and morbidity rate (Lillehei et al., 1955). The psychological trauma to both patients and parents awaiting a further major operative procedure for a period of years is difficult to evaluate but is likely to be considerable.

The difficulties of managing patients aged less than I year treated by total correction are related to cardiopulmonary bypass, to operative technique, and to the care in the immediate postoperative period.

Increased expertise in the use of cardiopulmonary bypass in patients weighing less than $7 \mathrm{~kg}$ is being generally acquired (Burnell et al., 1970). The basic flow rate of $2.41 . / \mathrm{m}^{2}$ per min agrees with other workers (Dobell et al., 1968), though we have found that moderate cooling only (mean $30-34^{\circ} \mathrm{C}$ ) is necessary. The use of the Bentley oxygenator has proved simple and convenient for our purposes: in our experience bubble oxygenators have not exhibited the disadvantages claimed by other workers (Burnell et al., 1970).

Our views on the value of digitalis during the operative and postoperative period have been previously detailed (Bristow and Griswold, 1965), as have the benefits of the routine use of atrial and ventricular pacemaker wires (Friesen et al., 1968).

In general the surgical technique used is that applied to larger patients. The use of a 'teflon' patch for the septal defect with careful placement of sutures is associated with freedom from the development of complete heart block, though right bundlebranch block was produced in some. Infundibular resection, carried out in all our patients, may be more hazardous in the smaller heart; damage to a sinus of Valsalva in I patient proved fatal. Enlargement of the right ventricular outflow tract by patching was necessary in 3 . This was not predicted from the preoperative angiogram, though this is in accord with our experience in older patients (Woodson et al., 1969).

That relief from right ventricular obstruction is satisfactorily achieved by infundibular resection is seen by the fall in right ventricular pressures from a preoperative mean of $83 \mathrm{mmHg}$ (range 100-70) to postoperative mean levels, taken at normal systemic pressure levels, of $40 \mathrm{mmHg}$ (range 60-30). Whether long-term haemodynamic results are satisfactory awaits information derived from catheter data at a later date. It seems unlikely, however, that these results will differ from the acceptable long-term haemodynamic results in children aged less than 4 years previously reported (Burnell et al., 1969).

\section{References}

Benson, P. F., Joseph, M. C., and Ross, D. N. (1962). Total surgical correction of Fallot's tetralogy in the first year of life. Lancet, 2, 326.

Bristow, J. D., and Griswold, H. E. (1965). The use of digitalis in cardiovascular surgery. Progress in Cardiovascular Diseases, 7, 387.

Brock, R. C. (1948). Pulmonary valvulotomy for the relief of congenital pulmonary stenosis. British Medical fournal, I, II2I.

Brock, R. C. (1959). Direct operations in tetralogy of Fallot. American fournal of Cardiology, 3, $\mathrm{I}$.

Burnell, R. H., Ghadiali, P. E., Joseph, M. C., and Paneth, M. (1970). Management of critical valvular outflow obstruction in neonates. Thorax, 25, 116.

Burnell, R. H., Woodson, R. D., Lees, M. H., Bristow, J. D., and Starr, A. (1969). Results of correction of tetralogy of Fallot in children under four years of age. fournal of Thoracic and Cardiovascular Surgery, 57, 153.

Dobell, A. R. C., Charette, E. P., and Chugtai, M. S. (1968). Correction of tetralogy of Fallot in the young child. Fournal of Thoracic and Cardiovascular Surgery, 55, 70.

Friesen, W. G., Woodson, R. D., Ames, A. W., Herr, R. H., Starr, A., and Kassebaume, D. G. (I968). A hemodynamic comparison of atrial and ventricular pacing in postoperative cardiac surgical patients. Fournal of Thoracic and Cardiovascular Surgery, 55, 271.

Gotsman, M. S., Beck, W., Barnard, C. N., O'Donovan, T. G., and Schrire, V. (1969). Results of repair of tetralogy of Fallot. Circulation, 40, 803.

Hallman, G. L. in discussion of Dobell, A. R. C., Charette, E. P., and Chugtai, M. S. (1968). Correction of tetralogy of Fallot in the young child. Fournal of Thoracic and Cardiovascular Surgery, 55, 70 .

Kaplan, S., Helmsworth, J. A., Ahearn, E. N., Benzing, G., Daoud, G., and Schwartz, D. C. (1968). Results of palliative procedures for tetralogy of Fallot in infants and young children. Annals of Thoracic Surgery, 5, 489.

Kirklin, J. W. (1969). Some problems in cardiovascular surgery. Annals of Thoracic Surgery, 7, 291.

Lillehei, C. W., Cohen, M., Warden, H. E., Read, R. C., Aust, J. B., DeWall, R. A., and Varco, R. L. (1955). Direct vision intracardiac surgical correction of the tetralogy of Fallot, pentalogy of Fallot and pulmonary atresia defects. Annals of Surgery, 142, 418.

McMillan, I. K. R., Johnson, A. M., and Machell, E. S. (1965). Total correction of tetralogy of Fallot in young children. British Medical fournal, $1,348$. 
Sabiston, D. C., Cornell, W. P., Criley, J. M., Neill, C. A., Ross, R. S., and Bahnson, H. T. (1964). The diagnosis and surgical correction of total obstruction of the right ventricle. Fournal of Thoracic and Cardiovascular Surgery, 48, 577.

Somerville, J., Yacoub, M., Ross, D. N., and Ross, K. (1969). Aorta to right pulmonary artery anastomosis (Waterston's operation) for cyanotic heart disease. Circulation, 39, 593.

Woodson, R. D., Burnell, R. H., Herr, R. H., Lees, M. H., and Starr, A. (1969). Surgical management of tetralogy of
Fallot in children under the age of four. Annals of Surgery, I69, 257.

Requests for reprints to G. M. Rees, Esq., F.R.C.S., St. Bartholomew's Hospital, London E.C.1

\section{Addendum}

Since this paper was submitted, four further patients with tetralogy of Fallot have been treated by total correction in the first year of life, without mortality. 